\title{
PARACHARTERGUS FRATERNUS (GRIBODO) \\ (HYMENOPTERA: VESPIDAE: POLISTINAE) USES VENOM \\ WHEN TAKING CATERPILLAR PREY
}

\author{
BY ERIC J. OLSON \\ 858 Watertown Street, West Newton, MA 02165 USA; \\ e-mail: eolson@world.std.com
}

\begin{abstract}
A forager of the eusocial wasp Parachartergus fraternus used its venom to subdue an unidentified small caterpillar, and another $P$. fraternus forager repeatedly stung a large saturniid caterpillar. In both instances, the wasp stung the larva and then waited nearby until the prey was fully paralyzed before biting it into manageable packets of meat. A review of the literature on social wasp foraging yielded no similar observations of a social wasp using venom when killing prey. Elements of the foraging behavior of $P$. fraternus are also seen in the foraging behavior of the Eumeninae, the solitary wasp taxon most closely related to eusocial wasps.
\end{abstract}

\section{INTRODUCTION}

A common generalization made about social wasps is that foragers kill prey by biting, and never use venom to subdue prey (Duncan 1939; Evans and West Eberhard 1970; Iwata 1976) or resort to its use only if the prey is large and struggling (Spradbery 1973; Edwards 1980). A corollary to this rule is that social wasp venom is reserved for defense, particularly of the nest and brood. In contrast, the majority of solitary hunting wasps do inject venom during prey capture. These different roles for venom have presumably led to the evolution of different venom compositions, since venom components designed to paralyze arthropod prey are unlikely to be best suited for the task of deterring nest predators, particularly vertebrates (Evans and West Eberhard 1970; Piek and Spanjer 1986). Exceptions to the rule that social

Manuscript received 14 December 1995. 
vespids kill without venom are reported to arise only when the risk of counterattack by the prey is exceptionally high. In contrast, I observed two foragers of the eusocial vespid Parachartergus fraternus envenomate relatively harmless prey. Both foragers attacked and killed nonurticating caterpillars; there was no struggle during either event, and the wasps' legs and mandibles were never employed directly in subduing the prey.

\section{MATERIALS AND METHODS}

The observations reported here took place in second growth tropical dry forest within the Guanacaste Conservation Area (Santa Rosa Sector), Guanacaste Province, Costa Rica. From 1989 to 1994, I conducted experiments in a $200+$ ha parcel of dry forest in Santa Rosa, examining the natural mortality agents of Rothschildia lebeau (Lepidoptera: Saturniidae). For these experiments, I set out $R$. lebeau larvae at natural densities (4 or fewer per tree) on 20 individuals of their host plant Casearia corymbosa (Flacourtiaceae). All experiments were conducted in mid-rainy season (June to August) of 1989 through 1992. Larvae were prevented from leaving branches by a ring of Tanglefoot Pest Barrier ${ }^{\circledR}$ applied to a tightly fitting plastic band wired about a limb base. Distal from this band, larvae were free to wander and feed in the foliage, and were observed to do so normally (Olson 1994).

\section{RESULTS}

\section{Observation 1}

Early in the rainy season in 1989, I noticed a smooth green caterpillar about $1.5 \mathrm{~cm}$ in length resting on the upper surface of a twig in the crown of a $2 \mathrm{~m}$ shrub growing just outside of my experimental plot. This larva was not one of my experimental larvae, and since it was killed and butchered almost instantly after I observed it, its true identity will remain unknown.

A Parachartergus fraternus forager was standing on the upper surface of a leaf a few centimeters off. The wasp took flight, lit on the dorsal surface of the larva, and touched it with the tip of its gaster, about midway along the body. The wasp immediately flew off and landed on a nearby leaf. The larva walked rapidly down the twig, then abruptly slowed and in less than one minute hung limply from the twig 
by only its anal prolegs. The wasp advanced and grasped the motionless caterpillar in its mandibles, then began to process it in the fashion of a typical vespid, masticating it into a packet of meat. It flew off with this packet.

\section{Observation 2}

Shortly after 16:00 on the 18th of August, 1991, I noted a Parachartergus fraternus forager resting on a leaf approximately 10 $\mathrm{cm}$ from one of my fourth instar Rothschildia lebeau larvae, 3.5 meters up in the crown of a C. corymbosa tree. I quickly began recording observations from the top of a tall stepladder, and at 16:13 the wasp flew over to the larva's leaf. About one minute later, the wasp walked alongside the larva and suddenly stung it on the side of one of its abdominal segments, then flew off to a nearby leaf. It did not pounce on the larva to deliver this sting; instead, it appeared that the wasp maintained contact with the leaf, whipped its gaster to the side to deliver the sting, then immediately flew clear. The larva twitched the moment it was stung, but did not attempt to escape. Instead it merely tucked its head and thoracic segments firmly under its anterior abdominal segments; this is the typical "escape" behavior of an $R$. lebeau larva. Even when pounced upon by a Polistes, or repeatedly poked and measured by a biologist, these larvae do not release their grip on their host plant, and rarely attempt to crawl away.

The wasp waited nearby for about one minute, preening its antennae while facing the larva. It then flew to the larva's leaf again, walked slowly to the larva, and imbibed a minute drop of hemolymph that was leaking from the puncture wound on the larva's side. The wasp did this while standing on the larva's leaf, not on the larva. Then at 16:16 it stung the larva again, in the same way and in the same region of the larva's body. As before, it flew quickly to a nearby leaf.

At 16:18 the larva began to lose muscular control, indicated by the fact that its anal prolegs lost their hold on the leaf. The larva attempted to reattach these prolegs, but at 16:20 the pair of prolegs immediately anterior to the anal prolegs also relaxed and came free. A few minutes later the next pair of prolegs lost their grip on the leaf, followed by the remaining prolegs, one pair at a time, over the next ten minutes. Before the most anterior pair of prolegs came free, the wasp returned to the larva's leaf and at 16:32 it stung the caterpillar a third time, again in the side of one of the mid-abdominal segments. Again the wasp flew 
off to wait nearby. At 16:35 the final pair of prolegs lost their hold on the midrib, and the larva hung only from its true legs, which still gripped the midrib of its leaf. The wasp remained off to one side, always facing the larva, occasionally preening its antennae, and then approached to imbibe more hemolymph.

At 16:40 the wasp tried to nip the underside of the larva with its mandibles, on the ventral surface near the larva's wounds. The wasp was still holding onto the leaf with several of its legs, and it had still not walked out onto the larva. The larva twitched slightly in response to the wasp's bite, lost its grip and fell $3.5 \mathrm{~m}$ to the ground, brushing by some foliage on a lower branch of the same tree on the way down. The wasp flew clear of the larva the instant it fell, lit on a nearby leaf, then immediately flew downwards, landing briefly on the foliage the larva had brushed past. There it walked rapidly about, apparently searching. Within seconds it flew downwards to the forest floor, its flight path a loose spiral. It landed on the ground within $10 \mathrm{~cm}$ of the larva, and walked directly over to it.

While the wasp chewed into it the larva remained motionless and appeared to be dead, but perhaps was just deeply paralyzed. Even if the larva could have recovered from the effect of the venom, it was soon hemorrhaging badly from the large wound made by the wasp's mandibles, and quickly became flaccid. At this point, the wasp began a prey-processing routine familiar to anyone who has observed foraging yellowjackets or Polistes: the wasp chewed off a piece of flesh and flew off with it, and then within 1 minute returned and chewed off a second piece from the ragged edge of the same wound. It again flew off in the same direction taken with the first piece, and about $1.5 \mathrm{~min}$ utes later it was back, presumably to bite off a third piece. I then captured it in a kill jar to preserve it as a voucher.

The elapsed time from discovery of the wasp in the crown of the tree until I captured it on the ground was about 35 minutes. The wasp may have begun its sequence of stings before I arrived, but I observed no droplet of hemolymph until after the first sting event recorded here.

The freshly killed larva measured $34 \mathrm{~mm}$ in length and its weight at the time of the attack (from a correlation of length on weight, $\mathrm{N}=25$ fourth instars, E. Olson, unpublished data) would have been between $1.5 \mathrm{~g}$ to $2 \mathrm{~g}$. A typical P. fraternus forager measures $11 \mathrm{~mm}$ in length, $3 \mathrm{~mm}$ across at the thorax, and weighs approximately $0.05 \mathrm{~g}$ wet weight. (I weighed and measured 4 freshly killed foragers with an analytical balance and obtained a mean $=0.04 \mathrm{~g}$.) 


\section{DISCUSSION}

Prey capture by social vespids is notoriously difficult to study, for these wasps skim rapidly over vegetation, and fly off quickly with their captures. Published observations of predation events tend to take the form of anecdotes scattered through the entomological literature at a low density. A few students of wasps have made more systematic observations, however. In particular, Raveret Richter (1988) observed hundreds of caterpillar kills by Polybia foragers, and never once saw them use their sting (M. Raveret Richter, personal communication). In the course of research examining natural mortality of the saturniid caterpillar Rothschildia lebeau, I observed three species of Polistes (usually instabilis, but once each $P$. canadensis and either $P$. major or $P$. carnifex) take larvae on six occasions, and I never saw these wasps use their sting. I also observed a Synoeca septentrionalis forager taking Euscirrhopterus poeyi (Noctuidae) caterpillars, and it also killed its prey only by biting. I have also observed this vespid foraging for pyralid larvae on mangrove trees, using its large, sturdy mandibles to rip open leaf rolls while searching for prey. These observations are consistent with those summarized in several major reviews of vespid wasp biology (Duncan 1939; Evans and West Eberhard 1970; Iwata 1976). These authors all state that social wasps kill by biting, and do not use their venom in prey capture.

There are a few reports of social wasps using their sting to subdue prey, however. In several instances it appears that the attacking wasp may have underestimated the fighting ability of its chosen prey. For example, a Vespa vulgaris forager was found stinging a bumblebee (Park-Beresford 1931), another V. vulgaris was found stinging a "hoverfly" about equal to it in size (O'Rourke 1945), and another Vespa sp. forager was observed stinging a dragonfly (Robbins 1938). In each of these cases, the wasp and its prey had fallen to the ground locked in combat, and the loud buzzing and general commotion attracted the attention of a passing naturalist. The wasp prevailed in each case, although O'Rourke (1945) observed that the wasp's wing was torn, presumably during its battle with the hoverfly. These observations indicate defensive, rather than predatory, stinging.

Rau (1930) reported an instance of a vespid-probably Vespula maculifrons according to Duncan (1939) - pursuing a large grasshopper, and stinging it whenever it caught up to it. Duncan (1939) discounts this report as a case of imputed behavior based on 
preconceptions. A report by Denton (1931) of a Dolichovespula maculata forager stinging a honeybee is likewise viewed with skepticism by Akre and Myhre (1992:20), who state flatly that "yellowjackets do not use their sting when capturing prey."

The regular use of the sting by one vespid species that sometimes attacks honeybees does appear to be well documented, however. Ishay et al. (1967) observed Vespa orientalis foragers capture Italian honeybees in Israel, and report that the wasps used their sting immediately after seizing a bee in flight, while simultaneously biting the bee in the vicinity of the head. They also report that the local Israeli race of honeybees routinely sting and kill attacking wasps during the multipleworker counterattacks which take place at their hive entrance. In another paper reporting vespid attacks on venomous prey, Matsuura and Sakagami (1973) report that although the Giant Hornet of Japan (Vespa mandarinia) can destroy even very large Italian honeybee colonies by biting one worker after another, they do use their stings in the fights required to subdue nests of other Vespa or of Vespula species.

Except for the somewhat discredited report by Rau (1930), the use of the sting in most of these situations is perhaps best interpreted as a reflexively defensive behavior than as a primary means of prey capture. The attacking wasp was either struggling with large prey while attempting to bite, or intent on rapidly subduing a venomous adversary.

Related to these observations, it appears that some foraging vespid species appear to perform a kind of risk assessment at the moment of encountering a potential prey item, and will reject prey items that are too large or dangerous. For example, I once saw a Polistes instabilis forager pounce on a large fifth instar $R$. lebeau larva and immediately fly clear, although $P$. instabilis readily takes smaller $R$. lebeau larvae (Olson 1994). D. H. Janzen has also observed vespids pounce on and then immediately fly off of very large caterpillars (personal communication).

Considering what is known about social vespid foraging, the behavior of Parachartergus fraternus raises some tantalizing possibilities about the foraging biology of this species. First, perhaps $P$. fraternus can attack a more diverse prey base in terms of both prey size and type, compared to the prey base of those vespids that kill through purely physical means.

Second, it may be that these wasps assess the condition of their prey before deciding to employ the sting, and assess the response to 
stinging of a prey item to determine whether to sting again. Sting number delivered by wasps in the generally solitary-wasp family Sphecidae is positively correlated with size and/or strength of prey (Steiner 1986). In fact, although sphecids nearly always paralyze their prey with venom, wasps in the subfamily Pemphredoninae effectively "paralyze" (thoroughly disable but do not kill) particularly small and helpless aphids by merely squeezing gently with their mandibles (Steiner 1986). Perhaps $P$. fraternus also will be shown to take very small prey with only its mandibles, but deliver venom in doses matched to its prey's size when it encounters a large prey item.

Has the use of the sting been reinvented by Parachartergus fraternus, or is this behavior conserved from the solitary predators from which social vespids evolved? Whether the sister group to the Vespidae is the Scoliidae or the Formiciidae (reviewed in Carpenter 1991), the use of the sting for prey capture is clearly the ancestral condition. It is certainly the rule in the Eumeninae, which are solitary vespids that form the sister group to all three social vespid subfamilies (Carpenter 1982). The Eumeninae prey almost exclusively on caterpillars (Evans and West Eberhard 1970), specializing on concealed larvae such as leaf rolling pyralids.

For eumenines, getting a larva out of a leafroll involves a "laborious extraction ... the wasp often poking its gaster in the shelter of the resisting caterpillar," and delivering "irregular" stings in the process (Steiner 1986:134). Their prey nearly always suffer randomly located stings on abdominal segments; precise deeply paralyzing stings to thoracic ganglia are delivered only after the larva is at least partly extracted (Steiner 1986). To my knowledge, the observation that the first stings by eumenines are delivered before the prey has been seized contrasts with all other accounts of prey capture by solitary wasps, in which the wasp first gains control of the prey with the use of the legs and/or mandibles, and then delivers precise paralyzing stings (Evans and West Eberhard 1970; Evans 1973; Steiner 1986).

It is at least suggestive that the closest relatives of the social wasps (1) prey on caterpillars, (2) without first pouncing on them, and (3) deliver imprecise stings to the abdominal segments. It is not yet possible to say even tentatively whether some of these eumenine behaviors are ancestral to the foraging behaviors of $P$. fraternus. Too little is known about prey capture by most vespid species, especially species in the many social genera found only in the tropics, to assess how the use 
of venom maps onto the most recent phylogenetic hypotheses (Carpenter 1991) for the social vespids and their solitary relatives.

\section{ACKNOWLEDGMENTS}

I thank J. M. Carpenter at the American Museum of Natural History for wasp identification, and D. H. Janzen for insisting that I get all the minutiae down when observing wasp behavior and other natural phenomena. Both D. H. Janzen and M. J. West Eberhard made useful comments on an earlier version of this paper, and Monica Raveret Richter suggested several key references. Much thanks also to Roger Blanco and other employees of the Guanacaste Conservation Area for their diligent stewardship efforts, and for their camaraderie during the years of my Ph.D. research. This study was supported by the Garden Club of America Grants Program in Tropical Botany, the Organization for Tropical Studies, and an NSF grant BSR 90-24770 to D. H. Janzen.

\section{Literature Cited}

Akre, R. D. and E. A. Myhre. 1992. Nesting biology and behavior of the bald-faced hornet, Dolichovespula maculata (L.) (Hymenoptera: Vespidae) in the Pacific Northwest. Melanderia 48: 1-33.

Carpenter, J. M. 1982. The phylogenetic relationships and natural classification of the Vespoidea. Syst. Entomol. 7: 11-38.

Carpenter, J. M. 1991. Phylogenetic relationships and the origin of social behavior in the Vespidae. In K. G. Ross and R. W. Matthews, eds., The Social Biology of Wasps, pp. 7-32. Ithaca, NY: Comstock Publishing Associates, Cornell Univ. Press.

Denton, S. B. 1931. Vespula maculata and Apis mellifera. Bull. Brooklyn Entomol. Soc. 26: 44 .

Duncan, C. D. 1939. A contribution to the biology of North American vespine wasps. Stanford Univ. Publ., Biol. Sci. 8: 1-272.

Edwards, R. 1980. Social Wasps: Their Biology and Control. East Grinstead, W. Sussex, England: Rentokil.

Evans, H. E. 1973. Wasp Farm. Garden City, NY: Doubleday and Co.

Evans, H. E. and M. J. West Eberhard. 1970. The Wasps. Ann Arbor: Univ. Michigan Press.

Ishay, J., H. Bytinkski-Salz, and A. Shulov. 1967. Contributions to the bionomics of the oriental hornet (Vespa orientalis Fab.). Israel J. Entomol. 2: 45-106.

Iwata, K. 1976. Evolution of Instinct: Comparative Ethology of Hymenoptera. New Delhi: Amerind Publishing Co.

Matsuura, M. and Sakagami, S. F. 1973. A bionomic sketch of the giant hornet, Vespa mandarinia, a serious pest for Japanese apiculture. J. Fac. Sci., Hokkaido Univ., Ser. VI, Zool. 19: 125162.

Olson, E. J. 1994. Dietary ecology of a tropical moth caterpillar, Rothschildia lebeau (Lepidoptera: Saturniidae). Unpublished Ph.D. dissertation. University of Pennsylvania, Philadelphia. 
O'Rourke, F. J. 1945. Methods used by wasps in killing prey. Irish Nat. J. 8: 238-241.

Park-Beresford, H. D. 1931. Wasp in combat. Irish Nat. J. 3: 223224.

Piek, T. and W. Spanjer. 1986. Chemistry and pharmacology of solitary wasp venoms. In

T. Piek, ed., Venoms of the Hymenoptera, pp. 161-307. London: Academic Press, Harcourt Brace Jovanovich.

Rau, P. 1930. Behavior notes on the yellow jacket Vespa germanica (Hymenoptera: Vespidae). Entomol. News 41: 185-190.

Raveret Richter, M. 1988. Prey hunting and interactions among social wasps (Hymenoptera: Vespidae) foragers and responses of caterpillars to hunting wasps. Doctoral dissertation. Cornell University, Ithaca, NY.

Robbins, J. M. 1938. Wasp versus dragonfly. Irish Nat. J. 7: 10-11.

Spradbery, J. P. 1973. Wasps: An Account of the Biology and Natural History of Solitary and Social Wasps. Seattle, WA: Univ. Washington Press.

Steiner, A. L. 1986. Stinging behaviour of solitary wasps. In T. Piek, ed., Venoms of the Hymenoptera, pp. 63-160. London: Academic Press, Harcourt Brace Jovanovich. 

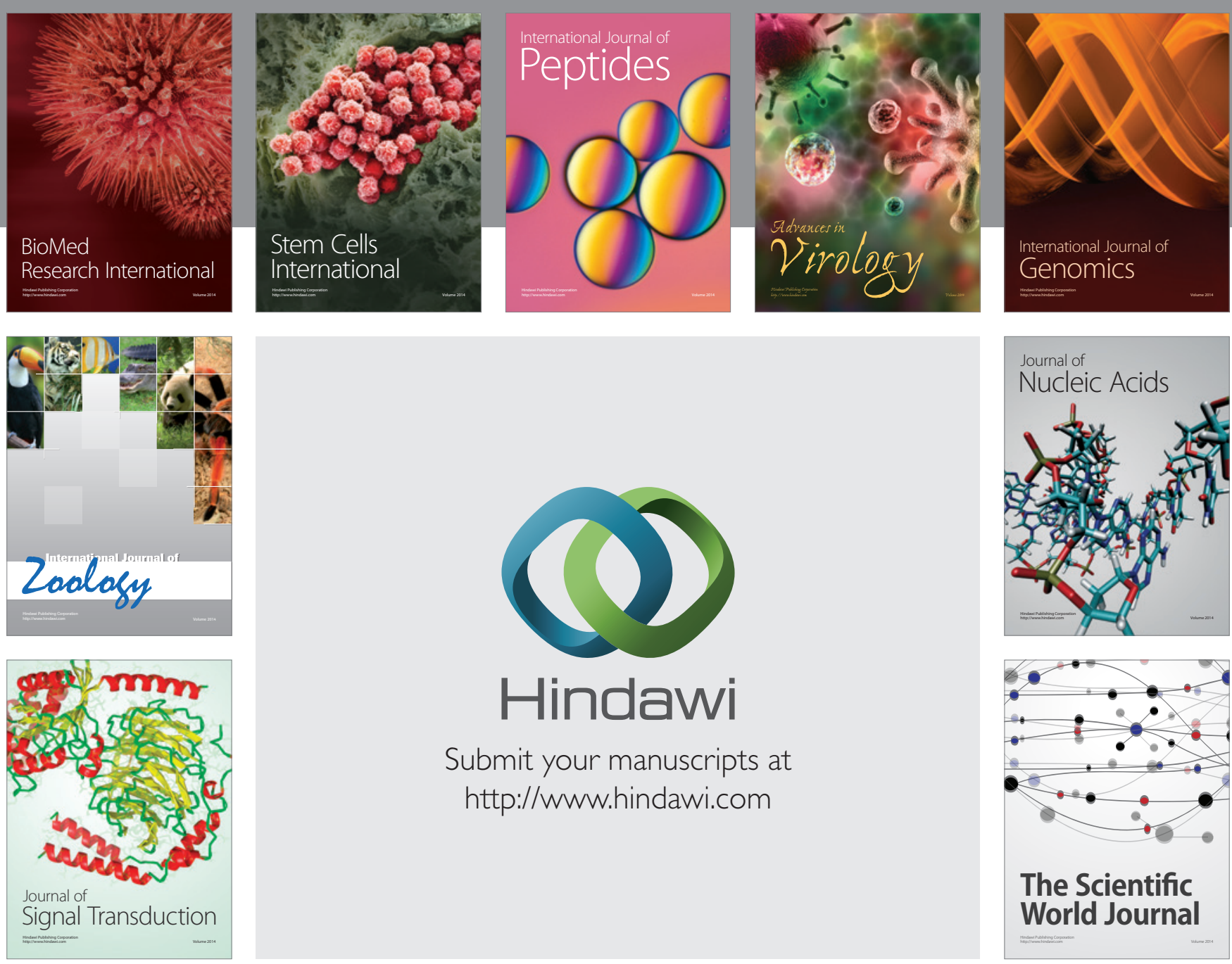

Submit your manuscripts at

http://www.hindawi.com
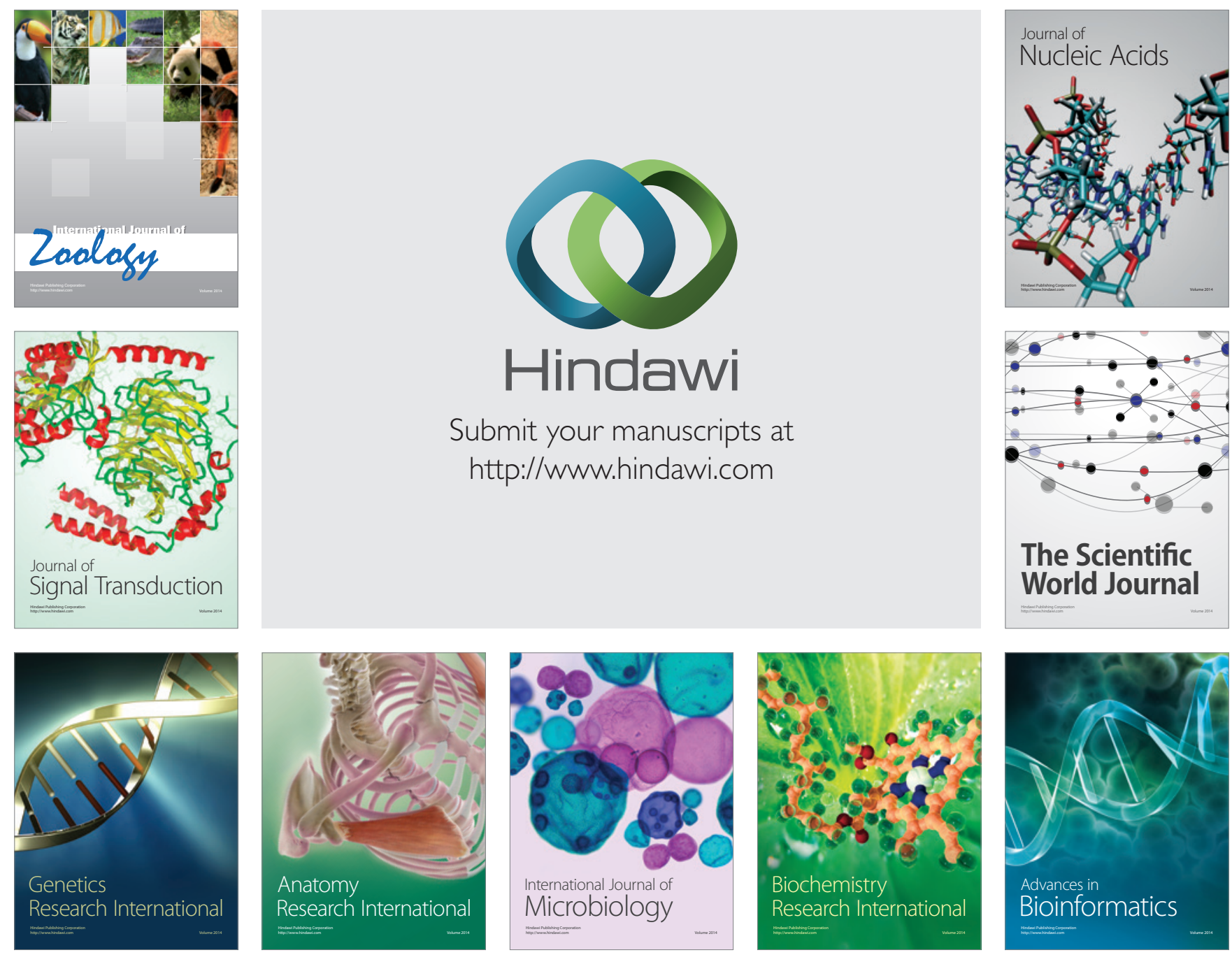

The Scientific World Journal
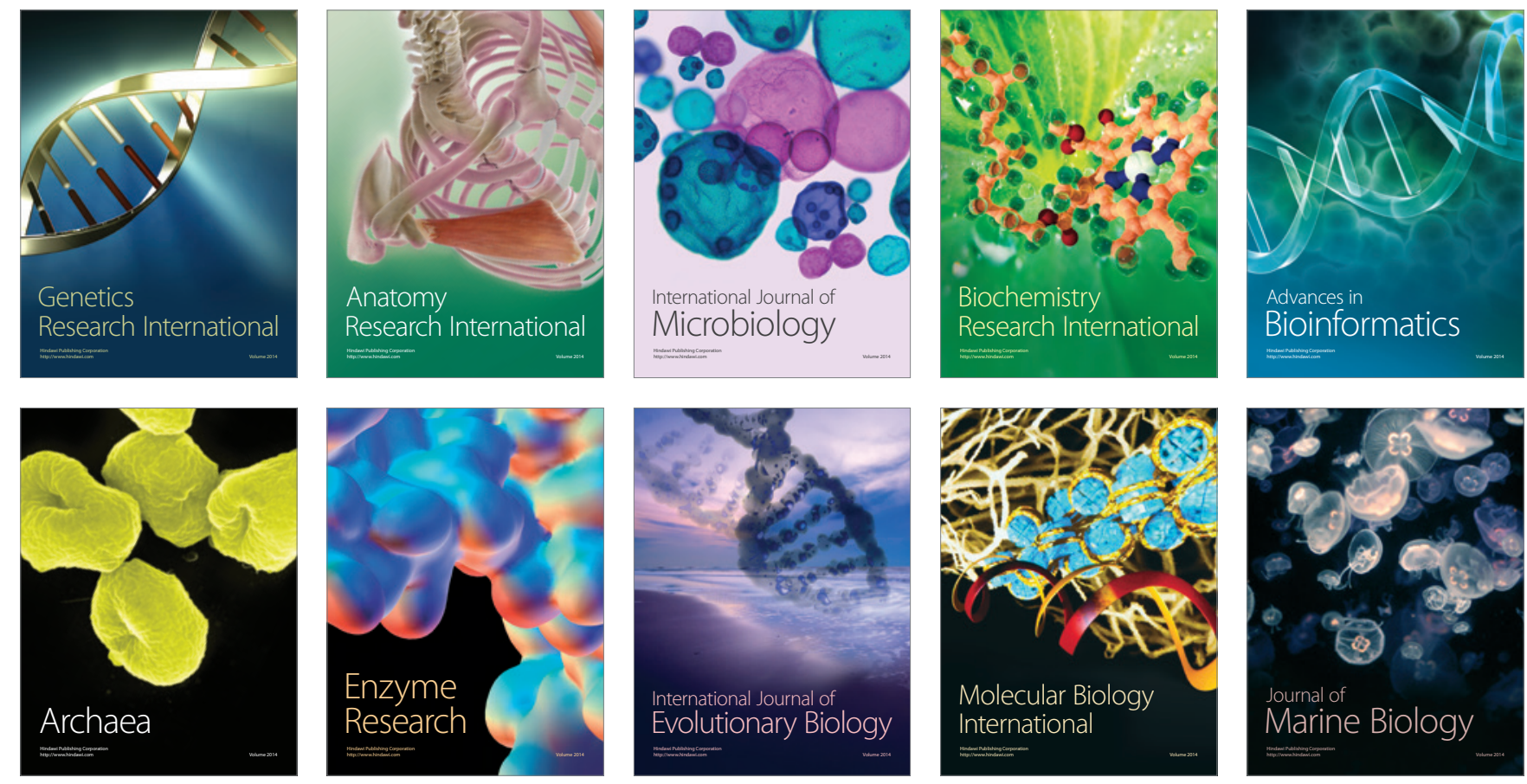